\title{
Increased Acetate Ester Production of Polyploid Industrial Brewer's Yeast Strains via Precise and Seamless "Self-cloning" Integration Strategy
}

\author{
Jian Dong ${ }^{1,}$, Kun-Qiang Hong ${ }^{1}$, Cui-Ying Zhang ${ }^{1}$, Sheng-Sheng Dong ${ }^{1}$, Xiao Li ${ }^{1}$, Ye-Fu Chen ${ }^{1}$, Dong- \\ Guang Xiao ${ }^{1}$
}

${ }^{1}$ Key Laboratory of Industrial Fermentation Microbiology, Ministry of Education, Tianjin Industrial Microbiology Key Laboratory, College of Biotechnology, Tianjin University of Science and Technology, Tianjin, China

* Corresponding author: Jian Dong, Key Laboratory of Industrial Fermentation Microbiology, Ministry of Education, Tianjin Industrial Microbiology Key Laboratory, College of Biotechnology, Tianjin University of Science and Technology, Tianjin, China; Tel: +86-02260601667; Fax: +8602260602298; E-mail: dongjian@tust.edu.cn

\begin{abstract}
Background: Enhancing the industrial yeast strains ethyl acetate yield through a precise and seamless genetic manipulation strategy without any extraneous DNA sequences is an essential requisite and significant demand.

Objectives: For increasing the ethyl acetate yield of industrial brewer's yeast strain, all the ATF1 alleles were overexpressed through "self-cloning" integration strategy.

Material and Methods: Escherichia coli strain DH5 $\alpha$ was utilized for plasmid construction. ATF1 alleles were overexpressed through a precise and seamless insertion of the PGK1 promoter in industrial brewer's yeast strain S6. In addition, growth rates, ATF1 mRNA levels, AATase activity, the fermentation performance of the engineered strains, and gas chromatography (GC) analysis was conducted.

Results: The two engineered strains (S6-P-12 and S6-P-30) overexpressed all ATF1 alleles but unaffected normal growth. The ATF1 mRNA levels of the S6-P-12 and S6-P-30 were all 4-fold higher than that of S6. The AATase (Alcohol acetyl transferases, encoded by ATF1 gene) activity of the two engineered strains was all 3-fold higher than that of the parent strain. In the beer fermentation at $10{ }^{\circ} \mathrm{C}$, the concentrations of ethyl acetate produced by the engineered strains S6-P-12 and S6-P-30 was increased to 23.98 and $24.00 \mathrm{mg} \mathrm{L}^{-1}$, respectively, about $20.44 \%$ and $20.54 \%$ higher than that of S6.

Conclusions: These results verify that the ethyl acetate yield could be enhanced by the overexpressed of ATF1 in the polyploid industrial brewer's yeast strains via “self-cloning" integration strategy. The present study provides a reference for target gene modification in the diploid or polyploid industrial yeast strains.

Keywords: Acetate Ester, ATF1, Polyploidy; PGK1
\end{abstract}

\section{Background}

During beer fermentation, the beer yeast strains produce higher alcohols and aromatic esters that affect the beer's organoleptic characteristics (1-3). These compounds are produced by yeast and have highly significant impacts on the smell and taste of the resulting beer. Beer quality is affected by the proportions of higher alcohols and esters in the fermentation production (4-6). However, the conventional genetic manipulation is difficult to regulate the synthesis of the higher alcohols and esters duo to polyploid industrial brewer's yeast strains cannot produce energetic spores. Thus, development of methods by which to modulate the proportions of the higher alcohols and esters is of great importance in the polyploid industrial brewer's yeast.

To achieve the maximum concentration of acetate ester, many attempts have been made to increase the activity of alcohol acetyl transferases (AATase). Previous reports have proved that transformants carrying multiple copies of the ATF1 gene exhibited higher AATase activity and produced greater concentrations of the acetate esters than the control strain with one ATF1 gene (7), but these transformants remained shuttle vectogene sequence. AATase activity was also increased 
through the overexpression the alcohol acetyltransferase gene (ATF1) by the PGK1p-ATF1 PGK1t overexpression cassette $(8,9)$. However, the resulting strains could not be approved by human usage due to the introduction of the restriction site. The BAT2 allelic genes were replaced by overexpression cassette PGK1p-ATF1-PGK1t for enhancing acetate ester synthesis in the industrial brewer's yeast strains (10). The method does affect an increase in the acetate ester content but the resultant yeast strains may be unsafe as the excision of the marker gene excision leaves behinds a single loxP site. Similarly, other target gene modifications using the recombinase-mediated marker excision system can result in unexpected deletions or chromosome rearrangements $(11,12)$. The "selfcloning” strategy was conducted as described by Dong, Walgate R, and Hirosawa $(13,14)$. In the recent study, this integration strategy has been used for overexpressing of the gene in the haploid yeast strains or to modify diploid strains $(15,16)$. Moreover, the method is useful in the introduction of the site-directed mutagenesis $(17,18)$. Therefore, we attempted to constructe polyploid industrial brewer's yeast strains with an increased the AATase I activity via "self-cloning" integration strategy.

\section{Objective}

In this study, $A T F 1$ alleles were overexpressed via "selfcloning” integration strategy in the S6 strain, the URA3 gene was used as the selectable marker. A plasmid carrying a fusion fragment ATF1p-PGK1p-ATF1 expression cassette was linearized and subjected to our integration protocol, resulting in strains without any extraneous DNA sequences. The mRNA levels of ATF1 and the acetyltransferase activity in the transformant were investigated. The strains generated with this approach showed an increased ethyl acetate yield in the beer fermentation at $10{ }^{\circ} \mathrm{C}$, demonstrating that our approach is an effective method for the development of the polyploid industrial brewer's yeast strains with an improved the taste of resulting beer.

\section{Materials and Methods}

\subsection{Materials}

The mediums used in experimental procedure were included of (LB medium: 10 g.L. $\mathrm{L}^{-1}$ tryptone, 5 g.L $\mathrm{L}^{-1}$ yeast extract, and 5 g. $\mathrm{L}^{-1} \mathrm{NaCl}, \mathrm{pH}$ 7.0) and ampicillin (100mg. $\mathrm{L}^{-1}$ ) that was used for plasmid selection, YEPD medium ( 1 g.L $\mathrm{L}^{-1}$ yeast extract, 2 g.L $\mathrm{L}^{-1}$ peptone, and 2 g.L ${ }^{1}$ glucose), SC-ura3 medium (6.7 g.L.-1 yeast nitrogen base without amino acids, supplemented with all the auxotrophic requirements except uracil, and 20 g. $\mathrm{L}^{-1}$ glucose), 5-Fluoroorotic acid (5-FOA) medium (6.7 g. $L^{-1}$ yeast nitrogen base without amino acids supplemented with all the auxotrophic requirements, 20 g. $\mathrm{L}^{-1}$ glucose, and 2 g.L $\mathrm{L}^{-1} 5$-fluoroorotic acid). All solid media used in this study have contained $2 \%$ agar. Fungal mRNA out kit, Quantscript RT kit and qRT-PCR SYBR green kit were obtained from Tiandz Biotech, Beijing, China. Ethyl acetate and isoamyl acetate were purchased from Merck (USA). BamHI and KpnI were purchased from Akara Biomedical Technology (Beijing) Co., Ltd. Escherichia coli strain DH5a was utilized for plasmid construction and propagation. 1.0 $\mathrm{ml}$ Tris- $\mathrm{HCl}$ ( $\mathrm{pH} 7.5,100$ mmol.L-1), 20 ul ethanol $(0.513 \mathrm{M})$, and $20 \mathrm{ul}$ Acetyl-CoA (10 mg.mL-1) were used for enzyme activity assays. Acetyl-CoA was purchased from Solarbio.

\subsection{Strains, Vectors, and Culture Conditions}

The genetic properties of all strains and plasmids are listed in Table 1. E. coil was incubated in the LuriaBertani medium at $37^{\circ} \mathrm{C}$, and ampicillin (100 mg.. ${ }^{-1}$ ) was added for plasmid selection. The yeast strain was grown at $30{ }^{\circ} \mathrm{C}$ in YEPD medium. SC-ura3 mediumat $30{ }^{\circ} \mathrm{C}$. 5-Fluoroorotic acid (5-FOA) medium was used only for the selection of uracil auxotrophic transformants.

\subsection{Plasmid Construction}

Plasmids YIplac211 was used for recombinant plasmids construction (19). DNA fragments were prepared as previously report (20). The primers are listed in Table 2.

Table 1. Strains and plasmids used in the current study

\begin{tabular}{|c|c|c|}
\hline Strains or plasmids & Relevant characteristic & Reference or source \\
\hline \multicolumn{3}{|c|}{$\begin{array}{ll}\text { Strains } \\
\end{array}$} \\
\hline E. coli. DH5a & $\begin{array}{l}\text { supE44 DlacU169(u 80lacZDM15) hsdR17 recAl endAl } \\
\text { gyrA96 thi-1 relA }\end{array}$ & Stratagene \\
\hline W303-1A & $M A T a$ & wan k et al (30) \\
\hline S6 & Wild-type industrial brewer's yeast & Hao et al(29) \\
\hline S6-ura3 & Wild-type industrial brewer's yeast(mutant URA3 gene) & This work \\
\hline S6-P-10 & $\begin{array}{l}\text { Wild-type industrial brewer's yeast(partial ATF1 allelic genes } \\
\text { overexpressed) }\end{array}$ & This work \\
\hline S6-P-12 & $\begin{array}{c}\text { Wild-type industrial brewer's yeast(all ATF1 allelic genes } \\
\text { overexpressed) }\end{array}$ & This work \\
\hline S6-P-30 & $\begin{array}{l}\text { Wild-type industrial brewer's yeast(all ATF1 allelic genes } \\
\text { overexpressed) }\end{array}$ & This work \\
\hline \multicolumn{3}{|c|}{$\begin{array}{lll}2 & \text { Plasmids }\end{array}$} \\
\hline YIplac211 & $\mathrm{Amp}^{\mathrm{r}} U R A 3$ & $(31.32)$ \\
\hline YIplac211-UPD & $A_{m p}{ }^{r} U R A 3$ containing ATF1p-PGK1p-ATF1 & This work \\
\hline
\end{tabular}


Table 2. Primers used in this study

\begin{tabular}{|c|c|c|}
\hline Primer name & sequence $^{\mathrm{a}}$ & $\begin{array}{c}\text { Restriction } \\
\text { site }\end{array}$ \\
\hline URA3-F & AGGAAGGAGCACAGACTTA & None \\
\hline URA3-R & GTTACTTGGTTCTGGCGAG & None \\
\hline pATF1-F & 5’CGCGGATCCGCCATAAATATTCCTGTAATGAC3’ & BamHI \\
\hline pATF1-R & 5’ATCAAGAATGTAATTTTCAGTTTTGGATAGATCAGTTAGAGAGAGCTGATAAATTGATG3’ & None \\
\hline pPGK-F & 5’GCACTTCATCAGTATCACAAATACCATCAATTTATCAGCTCTCTCTAАСTGATCTATCС3’ & None \\
\hline pPGK-R & 5’GCACGGGGGCCTGATTTTTCTCATCGATTTCATTCATGTTTTATATTTGTTGTAAAAAG3’ & None \\
\hline ATF1-F & 5’TCAAGGAAGTAATTATCTACTTTTTACAACAAATATAAAACATGAATGAAATCGATGAG3’ & None \\
\hline ATF1-R & 5’CGGGGTACCGCGGGGATAAAAATATCCG3’ & Kpnl \\
\hline $\begin{array}{l}\text { YIPlac211- } \\
\text { UPD-F }\end{array}$ & 5’CGGCTAATTTGTCTTCCA3' & None \\
\hline $\begin{array}{l}\text { YIPlac211- } \\
\text { UPD-R }\end{array}$ & 5'CGTGCTGCTACTCATCCT 3' & None \\
\hline $\begin{array}{l}\text { YIPlac211-UD- } \\
\text { F }\end{array}$ & 5’CCCCAGGCTTTACACTTTAT3’ & None \\
\hline $\begin{array}{l}\text { YIPlac211-UD- } \\
\text { R }\end{array}$ & 5’ATGCССАТТСТGAАTCATCT3' & None \\
\hline UD-F & 5’CGGCACTTCATCAGTATCAC3' & None \\
\hline UD-R & 5’CAGGCAGATTTCCСTCAAAG3' & None \\
\hline UP-F & 5’GCACAGGTAGATATAAGCTC3’ & None \\
\hline UP-R & 5’GTATGCGATAGTTCCTCACTC3’ & None \\
\hline PD-F & 5'GACTTCAACTCAAGACGCACAG3' & None \\
\hline PD-R & 5’GAAGACCGACCATCAGACAT3' & None \\
\hline RTATF1-F & 5’GGGTTCAATATACAAGGCTTCG3' & None \\
\hline RTATF1-R & 5’GCATCGGGCTCСTCTAACTG3’ & None \\
\hline ACT1-F & 5’TTATTGATAACGGTTCTGGTATG3’ & None \\
\hline ACT1-R & 5’CCTTGGTGTCTTGGTCTAC3’ & None \\
\hline
\end{tabular}

Table 3. The fermentation performance of the engineered strains and the parental strain

\begin{tabular}{lccccc}
\hline $\begin{array}{l}\text { Yeast } \\
\text { strains }\end{array}$ & $\begin{array}{c}\text { Weight loss of } \\
\mathbf{C O 2 , \mathbf { g }}\end{array}$ & $\begin{array}{c}\text { Ethanol, \%, v/v, } \\
\mathbf{2 0} \mathbf{C}\end{array}$ & $\begin{array}{c}\text { residual glucose, } \\
\text { g/liter }\end{array}$ & $\begin{array}{c}\text { Apparent degree of } \\
\text { fermentation, \% }\end{array}$ & $\begin{array}{c}\text { Real degree of } \\
\text { fermentation, \% }\end{array}$ \\
\hline S6 & $5.10 \pm 0.05$ & $4.64 \pm 0.02$ & $4.80 \pm 0.05$ & $74.68 \pm 0.05$ & $66.86 \pm 0.02$ \\
S6-P-12 & $5.00 \pm 0.05$ & $4.63 \pm 0.03$ & $4.80 \pm 0.10$ & $75.23 \pm 0.09$ & $66.82 \pm 0.04$ \\
S6-P-30 & $5.10 \pm 0.05$ & $4.62 \pm 0.04$ & $4.85 \pm 0.15$ & $73.29 \pm 0.07$ & $66.80 \pm 0.02$ \\
\hline
\end{tabular}

The fragment of the upstream flank of ATF1（U) was amplified from the genomic DAN of S6 strain using primer pairs $\mathrm{pATF} 1-\mathrm{F}$, containing the restriction site for BamHI and nucleotides +1 to +23 of the $\mathrm{U}$, and pATF1$\mathrm{R}$, nucleotides +1029 to +1047 of $\mathrm{U}$ (Table 2). The fragment of the PGK1 promoter (P) and the downstream homologous fragment of ATF1 (D) was similarly amplified using the pPGK1-F, pPGK1-R and ATF1-F, as well as ATF1-R primers. Primer ATF1-F containing the restriction site for Kpnl. In the fusion $\mathrm{PCR}$, overlapping sequences served as primers to amplify the sequences. PCR, in which the purified ATF1p and PGK1p fragments were invoked as templates without primer addition was first conducted. Cycling parameters were included of annealing temperature $55^{\circ} \mathrm{C}(45 \mathrm{~s})$, the subsequent extension step at $72{ }^{\circ} \mathrm{C}(1.5 \mathrm{~min})$, and 35 cycles in total. Then, PCR product was purified through gel extraction invoked as the template with primers U-F and P-R (Table 2) to generate gene sequence of the UP. Subsequently, these sequences were also purified and invoked as the template with primers U-F and D-R (Table 2) to generate gene sequence of the UPD. The resulting fusion PCR products were double digested by BamHI$K p n I$, purified through gel extraction and were inserted into the same enzyme pair-digested plasmid YIplac211, resulting in plasmids YIplac211-UPD (Table 3). The homologous fragments of this plasmid were amplified using the designed primers YIPlac211-UPD-F, YIPlac211-UPD-R and YIPlac211-UD-F, YIPlac211UD-R (Table 2).

\subsection{Yeast Transformation and Screening}

The mutant URA3 gene was amplified from genomic DNA isolated from the industrial strain W303-1A using primer pairs URA3-F and URA3-R. Then, the mutant URA3 gene fragment was transformed into the industrial brewer's yeast strain S6 using the LiAc method (21), creating the strain S6-ura3. Transformations were spread onto SC plates and verified by cultured on SC-5-FOA plates. The plasmid YIplac211-UPD was linearized with Nrul and transformed into industrial brewer's yeast strain S6ura3, using the LiAc method described by Schiestl and Gietz (20). The first-step resulting strains S6- $\Delta \mathrm{U}-\mathrm{U}$ were verified by primer pairs of YIPlac211-UPD-F / YIPlac211-UPD-R, YIPlac211-UD-F / YIPlac211-UD$\mathrm{R}$ (Table 2). Then, the transformant obtained from the first-step integration growth onto SC-5-FOA plates and verified by colony PCR, creating strains CLy12a-U-P (Table 1). To recovery the mutant URA3 gene (ura3), the second-step integration was cultured and carried out as lithium acetate procedure reported previously (21). Then, the yeast strains were spread onto SC plates and 
verified by culturing on SC-5-FOA plates. Standard molecular genetic techniques were used for nucleic acid manipulations (22).

\subsection{Real-time Quantitative PCR (RT-qPCR) and Enzyme Activity Assays}

Samples for total RNA extraction were prepared according to our previously work (16). The relative quantification of ATF1 and ACT1 mRNA was determined by qRT-PCRSYBR green kit using primer pairs RTATF-F, RTATF-R and ACT1-F, ACT1-R, respectively (Table 2 ). The quantitative real-time PCR was conducted using a Roche Light Cycler 480 RealTime PCR machine, and the final data were calculated using the threshold cycle $\left(2^{-\Delta \Delta \mathrm{CT}}\right)$ method (23).

The ATF1-encoded AATase activity was measured using the method reported by Fujii et al. (24). AATase I assays were conducted for $150 \mathrm{xg}$ at $30^{\circ} \mathrm{C}$ for $6 \mathrm{~h}$ in a reaction medium containing certain weight of centrifuged yeast cell, $1.0 \mathrm{ml}$ Tris- $\mathrm{HCl}(\mathrm{pH} 7.5,100$ mmol.L $\left.\mathrm{L}^{-1}\right), 20 \mathrm{ul}$ ethanol $(0.513 \mathrm{M})$, and $20 \mathrm{ul}$ AcetylCoA (10 mg. $\left.\mathrm{mL}^{-1}\right)$. The produced ethyl acetate's concentration of was measured by gas chromatography-mass spectrometry (GC-MS). One unit of AATase I activity was defined as the amount of enzyme per $1 \mathrm{~g}$ of yeast cells obtained by centrifugation at definite $\mathrm{g}$ force (you should say what $\mathrm{g}$ force or $\mathrm{rpm}$ ) that could produce $1 \mu \mathrm{mol}$ of ethyl acetate per $\mathrm{h}$ at $25^{\circ} \mathrm{C}$.

\subsection{Fermentation Test}

\subsubsection{Seed Culture}

Control strain and engineered strains were cultured in 5 $\mathrm{mL}$ of $11^{\circ} \mathrm{P}$ wort medium at $30{ }^{\circ} \mathrm{C}$ for $12 \mathrm{~h}$. Then transferred into $45 \mathrm{~mL}$ of the wort medium at $16^{\circ} \mathrm{C}$ for $36 \mathrm{~h}$.

\subsubsection{Beer Fermentation}

A volume of $15 \mathrm{~mL}$ of the primary culture was transferred into $135 \mathrm{~mL}$ of wort medium and incubated at $10{ }^{\circ} \mathrm{C}$ for $8-10$ days. The fermentation was processed untill the weight loss of $\mathrm{CO}_{2}$ after an interval period of $12 \mathrm{~h}$ was less than $0.1 \mathrm{~g}$.

\subsubsection{Fermentation Performance Analysis}

The fermentation performance of the $\mathrm{CO}_{2}$ weight loss, residual sugar, apparent degree of fermentation, real degree of fermentation and ethanol production were determined, respectively. Production of esters compounds was determined using gas chromatography (GC) analysis.

\subsubsection{Gas Chromatography (GC) Analysis}

Samples from the wort medium were filtered and distilled after fermentation and then were used for GC analysis. The analysis was performed according to our previously work (16).

\section{Results}

4.1. Construction of Engineered Brewer's Yeast Strains URA3 gene was mutated in parent strain S6 via transformation, resulting strain S6-ura3 was verified with SC plate and SC-5-FOA plate (Fig. 2 and Fig. 4). The two-step integration strategy is our previously work, which was performed to construct the engineered strains with overexpressing $A T F 1$ gene by the promoter PGK1p. The length of ATF1p, PGK1p and ATF1 was 1,048-, 1,479- and 1,046-bp respectively (Fig. 1). The resulting recombinants were verified via PCR using the primer pairs of YIPlac211-UPD-F / YIPlac211-UPD-R, YIPlac211-UD-F / YIPlac211-UD-R (Table 2) with S6-ura3 (negative) and plasmid YIplac211-UPD (positive) as controls.

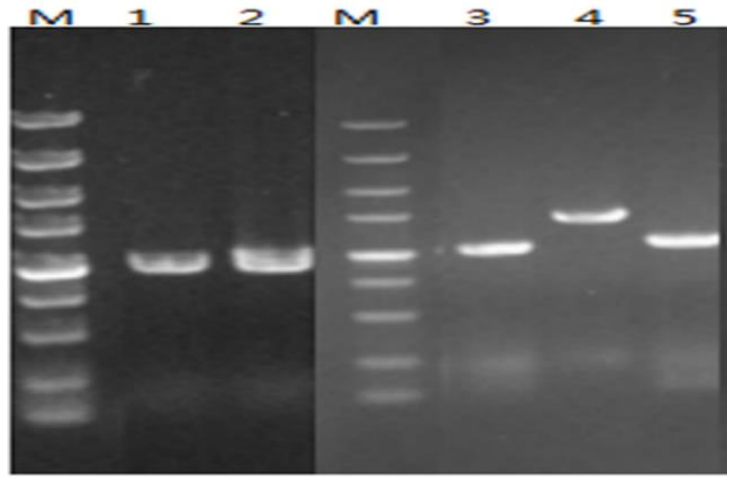

Figure 1: Agarose gel analysis and sequence analysis.

M, 5,000-bp DNA ladder marker; lane 1 (mutant gene ura3) and lane 2(gene URA3), PCR amplification results from the W303-1A and S6 genome, respectively, using primers URA3-F and URA3-R; lane 3, lane 4 , and lane 5, PCR amplification results from S6 genome, respectively, using primers pATF1-F / pATF1-R, pPGK-F / pPGK-R and ATF1F/ATF1-R

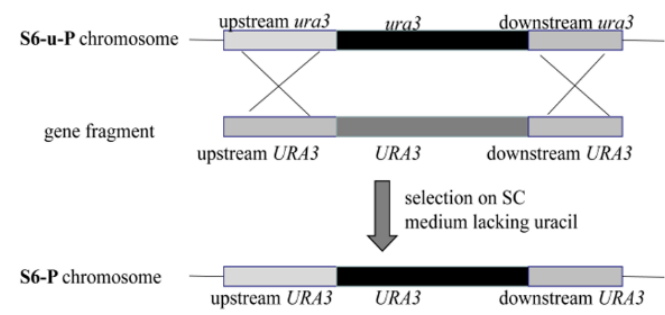

Figure 2. The procedure of recovery of the mutant gene ura3.

When UP-F and UP-R, PD-F and PD-R (Table 2) primer pairs were used to verify the recombinants, $P C R$ products were amplified with S6-ura3 negative control. When UD-F and UD-R were used to verify the recombinants, S6-P-10 appeared two lanes, S6-P-12 and S6-P-30 appeared one lane. Results showed PGK1 $p$ was inserted into upstream of the ORF of the gene ATF1. Furthermore, at least one ATF1 allelic gene of resulting strain S6-u-P-10 was inserted PGK1p and all ATF1 allelic gene of the S6-u-P-12 and S6-u-P-30 were inserted PGK1p. Moreover, results of sequencing results indicated the precise insertion of PGK1p in the 5'terminal of the target gene (ATF1) without any extraneous residual DNA. The mutant gene (ura3) and 
the normal gene (URA3) were compared the results of which are shown in the Figure 3 and Figure 4. The ura3 gene of S6-u-P was recovered via the method as described before.

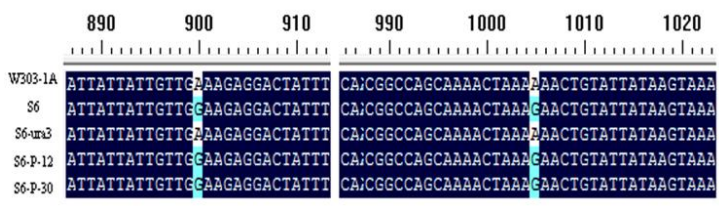

Figure 3. The genetic comparisons of URA3 gene, controlled W3031A, S6, S6-ura3, S6-P-12, and S6-P-30, using primers URA3-F and URA3-R.

In addition, we selected 36 colonies to verify URA3 marker elimination. The frequency of pop-up is approximately $10^{-4}$, which is similar to the his $G$ repeats reported previously (25). As well, the desired insertion occurred with a frequency of approximately $10^{-5}$, which are consistent with our previous studies $(15,16)$.

\subsection{Analysis of ATF1 mRNA Levels and Measurement of AATase Activity}

The ATF1 mRNA levels and measurement of AATase activity of parental strain and engineered strains were performed, respectively. The RT-qPCR results and AATase activity in the engineered strain were 4- and 3fold higher than that of parental strain, respectively (Fig. 5A and Fig. 5B). These results confirmed that the ATF1 gene was overexpressing by PGK1p insertion with an increase of the gene expression and the enzyme activity.

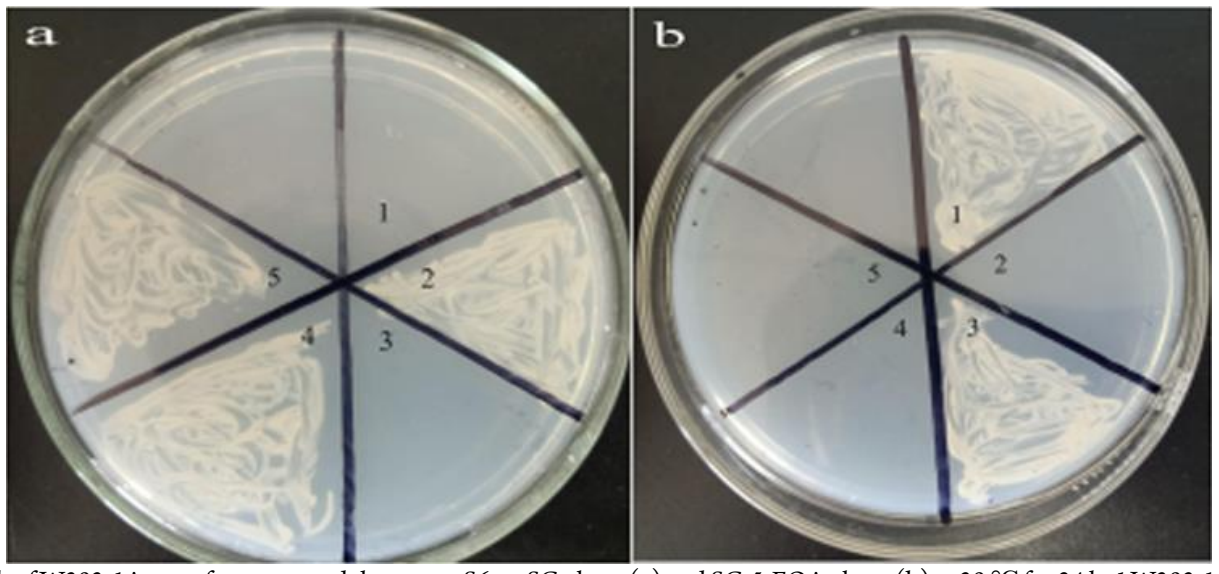

Figure 4. Growth of W303-1A, transformants, and the parent S6 on SC plates (a) and SC-5-FOA plates (b) at $30^{\circ} \mathrm{C}$ for $24 \mathrm{~h} .1 \mathrm{~W} 303-1 \mathrm{~A}, 2$ parent strain S6, 3 S6-ura3, 4, and 5 show the transformants
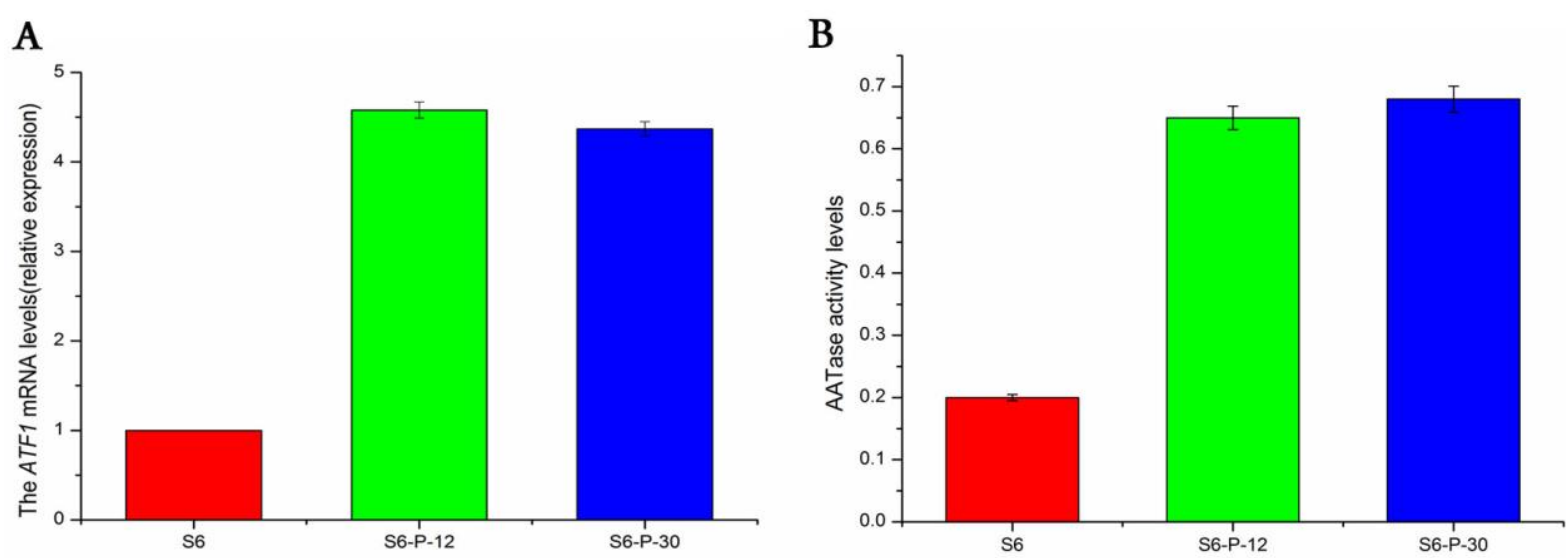

Figure 5. (A) The ATF1 mRNA levels (relative expression) and (B) AATase activity levels of the strains S6, S6-P-12, and S6-P-30. The experiments were repeated three times. Data are the average of THE three independent experiments. Error bars represent \pm SD.

\subsection{Fermentation Performance of Engineered Strains}

The growth performances of the engineered strains and parent strain were tasted, respectively, and there are no any significant distinctions (Fig. 6). Then, the fermentation performance of the engineered strains were performed, and results were compared with those obtained from the parent S6. The results (Table 3) show no obvious distinction among the tested strains.

\subsection{Effects of ATF1 Overexpression on the Production of Volatile Flavor Compounds}

After beer fermentation, the concentrations of the ester components were determined by GC analysis. As shown in Figure 7 and Table 4, the concentration of ethyl acetate produced by the engineered strains S6-P-12 and S6-P-30 increased to 23.98 and $24.00 \mathrm{mg} \mathrm{L}^{-1}$, respectively, or $20.44 \%$ and $20.54 \%$ higher than that produced by 56 . 
There was not an obvious distinctions in the isoamyl acetate content were observed in the fermentation samples of the tested strains. These results confirmed that the two-step integration strategy can overexpress $A T F 1$ gene via $P G K 1$ promoter seamless insertion and led to an increase in the ethyl acetate synthesis.

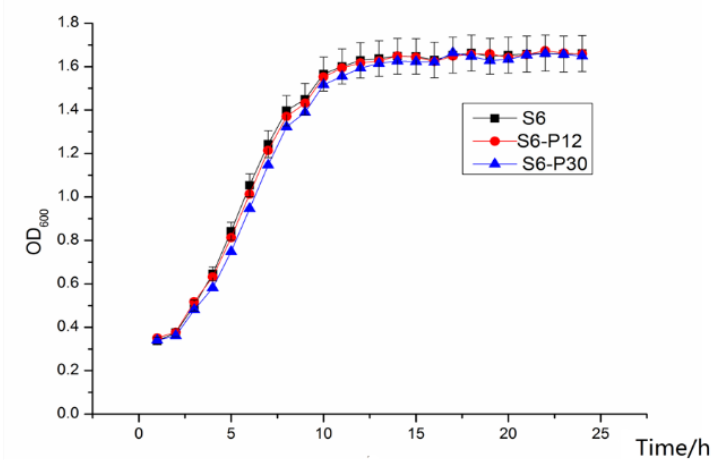

Figure 6. The growth curve of the parent strain and the engineering strains. Data are the average of the three independent experiments. Error bars represent \pm SD.

Table 4. The volatile flavor compound productions of the engineered strains and the parental strain

\begin{tabular}{lcc}
\hline $\begin{array}{l}\text { Yeast } \\
\text { strains }\end{array}$ & Ethyl acetate $(\mathbf{m g} / \mathbf{L})$ & Isoamyl acetate $(\mathbf{m g} / \mathbf{L})$ \\
\hline S6 & $19.91 \pm 0.15$ & $2.98 \pm 0.12$ \\
S6-P-12 & $23.98 \pm 0.07$ & $2.98 \pm 0.06$ \\
S6-P-30 & $24.00 \pm 0.13$ & $3.34 \pm 0.24$ \\
\hline
\end{tabular}

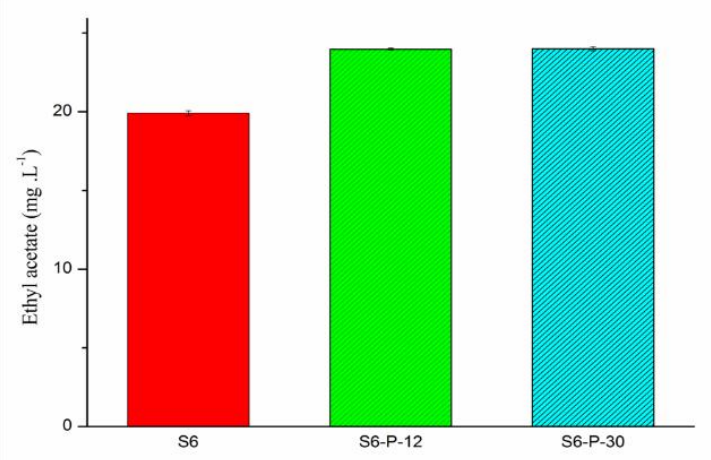

Figure 7. The production of ethyl esters in the recombinant strain: S6P-12, S6-P-30, and S6. Data are the average of the three independent experiments. Error bars represent $\pm \mathrm{SD}$.

\section{Discussion}

In our work, we used polyploid industrial brewer's yeast; S6, as the parent strain. Meanwhile, we have overexpressed all ATF1 alleles in the industrial brewer's yeast through insertion of the PGK1p. The method is also effective for the polyploid yeast strain with an equal frequency of hisG repeats (25), and is less timeconsuming compared to the site-specific recombinase and the delitto perfetto system (26) because only a single transformation is required in this case. Importantly, "self-cloning" integration strategy can overexpress all ATF1 alleles gene without any further genetic manipulations $(13,15,16,27)$.
The conventional genetic manipulation is easy to regulate the higher alcohols and esters synthesis of the haploid yeast strains, however, ineffective for the industrial brewer's yeast due to the fact that it cannot produce energetic spores. Thus, the introduction of the methods which could modulate the proportions of the higher alcohols and esters content is of great importance in the polyploid industrial brewer's yeast. This method provide an useful method to realize the site-directed mutagenesis (28) and genes overexpression (14) in the industrial strains.

\section{Conclusions}

The harmonious complexity of the perceived flavor in the industrial brewer's yeast is significantly important to ensure the best test in the end product (29). In the work, $A T F 1$ gene was overexpressed in polyploid industrial brewer's yeast through the insertion of the PGK1 promoter. Brewing with all ATF1 allelic gene overexpression recombinant industrial brewer's yeast strains increased ethyl acetate yield. Our investigations show that the ATF1 gene expression levels and AATase activity of the beer brewed with the strains with all overexpressed ATF1 copies (S6-P-12 and S6-P-30) were increased compared with that of parent strain S6. The engineered strain with stable fermentation property provided a new dimension of the optimized strains research in the industrial brewer's yeast.

The industrial brewer's yeast strains cannot produce energetic spores as the strains are usually diploid and polyploid. Therefore, the conventional genetic manipulation is difficult to obtain ideal brewer's yeast strains. Our work demonstrates that two-step integration protocol may be helpful to get good industrial brewer's yeast strains. Moreover, the resulting mutant, S6-P, in which the PGK1p derived from the starting strain, was seamlessly inserted into the upstream of the ATF1 without an introduction of the restriction sites $(13,15,16)$. As well, our method is effective as marker excision occurred with an equal frequency of the his $G$ repeats and can avoid unexpected deletions or chromosome rearrangements due to the none foreign sequences (a single loxP site) remaining after yeast genetic modification $(\mathrm{GM})(11,12,30)$. Therefore, the engineered strain would be securely applied and accepted by the consumers.

In summary, we have constructed high ester productivity brewer's yeast strains S6-P-12 and S6-P-30. Consequently, all ATF1 allelic genes were overexpressed in the engineered strains with any heterologous sequences in their sequences. Therefore, the engineered strain would be easily accepted by the consumers. With a better understanding of and further research into the genetically modified organisms, these will likely be widely used in the modulation of the yield of volatile flavor in the industrial brewer's yeast strains, respectively. 


\section{Acknowledgments}

This work was supported by the National Natural Science Foundation of China (31671838), National Natural Science Foundation of China (31471724), The National Key Research and Development Program of China (2016YFD0400505), the National High Technology Research and Development Program of China (Grant No. 2013AA102108) and Major Project of Research Program on Applied Fundamentals and Advanced Technologies of Tianjin (14JCZDJC32900).

\section{Conflicts of Interest}

There is no conflict of interest.

\section{Author's Contribution}

Jian Dong and Kun-Qiang Hong have contributed equally to the article.

\section{Compliance with Ethics Requirements}

This article does not contain any studies with human or animal subjects.

\section{References}

1. Styger G, Prior B, Bauer FF. Wine flavor and aroma. $J$ Ind Microbiol Biotechnol. 2011;38(9):1145-1159. doi: 10.1007/s10295-011-1018-4 pmid: 21786136

2. Swiegers JH, Pretorius IS. Yeast modulation of wine flavor. Adv Appl Microbiol. 2005;57:131-175. doi: 10.1016/S0065-2164(05)57005-9 pmid: 16002012

3. Swiegers JH, Bartowsky EJ, Henschke PA, Pretorius IS. Yeast and bacterial modulation of wine aroma and flavour. Austr J Grape Wine Res. 2005;11(2):139-173. doi: 10.1111/j.1755-0238.2005.tb00285.x

4. Styger G, Jacobson D, Bauer FF. Identifying genes that impact on aroma profiles produced by Saccharomyces cerevisiae and the production of higher alcohols. Appl Microbiol Biotechnol. 2011;91(3):713-730. doi: 10.1007/s00253-011-3237-z pmid: 21547456

5. Rankine BC. Formation of higher alcohols by wine yeasts, and relationship to taste thresholds. J Sci Food Agricult. 1967;18(12):583-589. doi: 10.1002/jsfa.2740181208

6. Saerens SM, Verbelen PJ, Vanbeneden N, Thevelein JM, Delvaux FR. Monitoring the influence of highgravity brewing and fermentation temperature on flavour formation by analysis of gene expression levels in brewing yeast. Appl Microbiol Biotechnol. 2008;80(6):1039-1051. doi: 10.1007/s00253-0081645-5 pmid: 18751696

7. Fujii $\mathrm{T}$, Nagasawa N, Iwamatsu A, Bogaki T, Tamai $Y$, Hamachi M. Molecular cloning, sequence analysis, and expression of the yeast alcohol acetyltransferase gene. Appl Environ Microbiol. 1994;60(8):2786-2792. pmid: 8085822

8. Lilly M, Lambrechts MG, Pretorius IS. Effect of increased yeast alcohol acetyltransferase activity on flavor profiles of wine and distillates. Appl Environ Microbiol. 2000;66(2):744-753. doi: 10.1128/aem.66.2.744-753.2000 pmid: 10653746

9. Lilly M, Bauer FF, Lambrechts MG, Swiegers JH, Cozzolino D, Pretorius IS. The effect of increased yeast alcohol acetyltransferase and esterase activity on the flavour profiles of wine and distillates. Yeast. 2006;23(9):641-659. doi: 10.1002/yea.1382 pmid: 16845703

10. Zhang C-Y, Liu Y-L, Qi Y-N, Zhang J-W, Dai L-H, Lin $\mathrm{X}$, et al. Increased esters and decreased higher alcohols production by engineered brewer's yeast strains. Eur Food Res Technol. 2013;236(6):1009-1014. doi: 10.1007/s00217-013-1966-1

11. Delneri D, Tomlin GC, Wixon JL, Hutter A, Sefton M, Louis EJ, et al. Exploring redundancy in the yeast genome: an improved strategy for use of the cre-loxP system. Gene. 2000;252(1-2):127-135. doi: 10.1016/s0378-1119(00)00217-1

12. Dequin $S$. The potential of genetic engineering for improving brewing, wine-making and baking yeasts. Appl Microbiol Biotechnol. 2001;56(5-6):577-588. pmid: 11601604

13. Walgate R. Genetic manipulation: Britain may exempt "self-cloning". Nature. 1979;277(5698):589. pmid: 370609

14. Hirosawa I, Aritomi K, Hoshida H, Kashiwagi S, Nishizawa Y, Akada R. Construction of a self-cloning sake yeast that overexpresses alcohol acetyltransferase gene by a two-step gene replacement protocol. Appl Microbiol Biotechnol. 2004;65(1):68-73. doi: 10.1007/s00253-004-1563-0 pmid: 14758521

15. Dong J, Wang G, Zhang C, Tan H, Sun X, Wu M, et al. A two-step integration method for seamless gene deletion in baker's yeast. Anal Biochem. 2013;439(1):30-36. doi: 10.1016/j.ab.2013.04.005 pmid: 23597844

16. Dong J, Xu H, Zhao L, Chen Y, Zhang C, Guo X, et al. Enhanced acetate ester production of Chinese liquor yeast by overexpressing ATF1 through precise and seamless insertion of PGK1 promoter. J Ind Microbiol Biotechnol. 2014;41(12):1823-1828. doi: 10.1007/s10295-014-1522-4 pmid: 25306884

17. Hashimoto S, Ogura M, Aritomi K, Hoshida $H$, Nishizawa Y, Akada R. Isolation of auxotrophic mutants of diploid industrial yeast strains after UV mutagenesis. Appl Environ Microbiol. 2005;71(1):312-319. doi: 10.1128/AEM.71.1.312-319.2005 pmid: 15640203

18. Jacq C, Alt-Morbe J, Andre B, Arnold W, Bahr A, Ballesta JP, et al. The nucleotide sequence of Saccharomyces cerevisiae chromosome IV. Nature. 1997;387(6632 Suppl):75-78. pmid: 9169867

19. Gietz RD, Sugino A. New yeast-Escherichia coli shuttle vectors constructed with in vitro mutagenized yeast genes lacking six-base pair restriction sites. Gene. 1988;74(2):527-534. doi: 10.1016/03781119(88)90185-0 pmid: 3073106

20. Sambrook J, Russell D. Molecular cloning: a laboratory manual. New York: CSHL press; 2001.

21. Gietz RD, Schiestl RH, Willems AR, Woods RA. Studies on the transformation of intact yeast cells by the LiAc/SS-DNA/PEG procedure. Yeast. 1995;11(4):355-360. doi: 10.1002/yea.320110408 pmid: 7785336

22. Sambrook J, Russell D. Molecular cloning: a laboratory manual. Cold Spring Cold Spring Harbor Laboratory Press; 2001.

23. Livak KJ, Schmittgen TD. Analysis of relative gene expression data using real-time quantitative PCR and 
the 2(-Delta Delta C(T)) Method. Methods. 2001;25(4):402-408. doi: 10.1006/meth.2001.1262 pmid: 11846609

24. Fujii T, Yoshimoto H, Tamai Y. Acetate ester production by Saccharomyces cerevisiae lacking the ATF1 gene encoding the alcohol acetyltransferase. $J$ Ferment Bioeng. 1996;81(6):538-542. doi: $10.1016 / 0922-338 \times(96) 81476-0$

25. Alani E, Cao L, Kleckner N. A method for gene disruption that allows repeated use of URA3 selection in the construction of multiply disrupted yeast strains. Genetics. 1987;116(4):541-545. pmid: 3305158

26. Hao X, Xiao D-G, Zhang C-Y, Chen Y-F. Influence of nutrients on proteinase A activity in draft beer during fermentation. Int J Food Sci Technol. 2010;45(6):11691174. doi: $10.1111 /$ j.1365-2621.2010.02252.x
27. Fonzi WA, Irwin MY. Isogenic strain construction and gene mapping in Candida albicans. Genetics. 1993;134(3):717-728. pmid: 8349105

28. Storici F, Lewis LK, Resnick MA. In vivo site-directed mutagenesis using oligonucleotides. Nat Biotechnol. 2001;19(8):773-776. doi: 10.1038/90837 pmid: 11479573

29. Zhao YP, Zheng XP, Song P, Sun ZL, Tian TT. Characterization of Volatiles in the Six Most WellKnown Distilled Spirits. J Am Soc Brew Chem. 2018;71(3):161-169. doi: 10.1094/asbcj-2013-062501

30. Wach A, Brachat A, Pohlmann R, Philippsen P. New heterologous modules for classical or PCR-based gene disruptions in Saccharomyces cerevisiae. Yeast. 1994;10(13):1793-1808. pmid: 7747518 